\title{
Salvianolic acid B inhibits the progression of liver fibrosis in rats via modulation of the Hedgehog signaling pathway
}

\author{
SHANJUN TAO ${ }^{1,2}$, RENJIE DUAN $^{1}$, TONG XU $^{1}$, JIAO HONG $^{1}$, WENJIE GU $^{1}$, AIQIN LIN $^{1}$, \\ LIKAI LIAN $^{1}$, HAOYU HUANG ${ }^{2}$, JIANGTAO LU ${ }^{2}$ and TIECHEN LI ${ }^{1}$ \\ ${ }^{1}$ Department of Medical Biology, School of Preclinical Medicine; ${ }^{2}$ Department of Clinical Biochemistry, \\ School of Laboratory Medicine, Wannan Medical College, Wuhu, Anhui 241000, P.R. China
}

Received March 9, 2021; Accepted November 16, 2021

DOI: $10.3892 / \mathrm{etm} .2021 .11039$

\begin{abstract}
Salvianolic acid B (Sal B) has previously reported anti-hepatic fibrosis effects, though it is not clear if it can inhibit hepatic fibrosis by regulating the hedgehog $(\mathrm{Hh})$ signaling pathway. The aim of the present study was to explore the roles and mechanism of Sal B in preventing and treating liver fibrosis in rats. The study also aimed to determine the role of the Hh signaling pathway in this process. A rat model of liver fibrosis was induced through the subcutaneous injection of 50\% carbon tetrachloride, followed by treatment with Sal B. After gavage, blood was collected to detect serum markers of liver injury. The degree of liver fibrosis and tissue damage was assessed using histopathological analysis. Western blotting and reverse transcription-quantitative PCR were used to detect the expression levels of TGF- $\beta 1$ and $\mathrm{Hh}$ signaling pathway-related genes, including Sonic hedgehog (Shh) protein, membrane protein receptor protein patched homolog 1 (Ptch1), membrane protein receptor Smoothened (Smo) and transcription factor glioma-associated oncogene homolog 1 (Gli1). Serum alanine aminotransferase, aspartate aminotransferase and total bilirubin levels were decreased, whilst levels of albumin were increased in rats with liver fibrosis that were treated with Sal B $(\mathrm{P}<0.05)$. Additionally, significant increases in TGF- $\beta 1$, Shh, Ptch1, Smo, Gli1 and $\alpha$-smooth muscle actin expression levels were observed in the liver tissues of rats with hepatic fibrosis $(\mathrm{P}<0.05)$. However, Sal B treatment significantly reduced the expression levels of these proteins $(\mathrm{P}<0.05)$. In conclusion, the results of the present study suggested that the Hh signaling pathway may be activated during the process of rat liver fibrosis. Thus, Sal B may exert its anti-hepatic fibrosis effects, at least in part, by inhibiting the activation of the Hh signaling pathway.
\end{abstract}

Correspondence to: Dr Tiechen Li, Department of Medical Biology, School of Preclinical Medicine, Wannan Medical College, 22 Wenchang West Road, Wuhu, Anhui 241000, P.R. China

E-mail: 20430151@qq.com

Key words: salvianolic acid B, liver fibrosis, TGF- $\beta 1, \alpha$-smooth muscle actin, hedgehog signaling pathway

\section{Introduction}

Liver fibrosis is a chronic repair response caused by various stimulus injuries, including ethanol, viruses, toxins or various drugs (1). Due to an imbalance between the degradation and synthesis of the extracellular matrix (ECM), normal hepatic structures are destroyed by progressively increasing levels of ECM in the liver parenchyma (1). Liver fibrosis is a common and frequently occurring clinical disease that can further develop into liver cirrhosis or hepatocellular carcinoma (2). However, this process is reversible $(3,4)$, and thus it is critical to prevent chronic liver disease from developing into cirrhosis and liver cancer.

Hepatic stellate cells (HSCs) serve a key role in the development of liver fibrosis, as they are the primary target cell affected by a range of fibrotic factors, such as Platelet-derived growth factor (PDGF) and transforming growth factor $\beta$ (TGF- $\beta$ ) (5-7). The hedgehog (Hh) signaling pathway is the key mediator of several basic processes in embryonic development and serves a vital role in controlling cell fate, differentiation, survival and proliferation $(8,9)$. It has been demonstrated that Hh ligands are released by injured liver cells in the process of liver fibrosis, which bind to the membrane receptor protein patched homolog 1 (Ptch1) on the surface of HSCs, releasing the inhibitory effect of Ptch1 on the membrane receptor Smoothened (Smo). The entry of the full-length glioma-associated oncogene homolog 1 (Gli; a nuclear transcription factor) into the nucleus is promoted by activated Smo, which in turn activates HSCs to promote transformation into myofibroblasts (MFBs); MFBs then secrete numerous collagen fibers, leading to liver fibrosis (10).

Salvianolic acid B (Sal B; an aromatic acid compound) is the primary water-soluble component of Salvia miltiorrhiza, which has been revealed to possess strong antioxidant activity (11) and exert protective effects on blood vessels, the pancreas and other tissues (12). Sal B has been demonstrated to improve rat vascular endothelial function by inhibiting endothelial cell apoptosis and reducing pancreatic morphological injury by decreasing the concentration of pancreatic tissue malondialdehyde $(12,13)$. Sal B has also been used in the treatment of chronic liver diseases, particularly in the treatment of liver fibrosis (14). Currently, to the best of our knowledge, only the study by Yu et al (15) has used liver fibrotic mice as a 
model to study whether Sal B inhibits the activation and proliferation of HSCs by interfering with the Hh signaling pathway. Additionally, the study only assessed the levels of Ptch1, Smo and Gli2 genes in the Hh signaling pathway using reverse transcription-quantitative (RT-q)PCR. Thus, it is necessary to conduct further studies to evaluate whether Sal B can affect rat liver fibrosis through the Hh signaling pathway.

In the present study, a rat model of liver fibrosis was induced to evaluate the roles of Sal B in liver fibrosis and its influence on the Hh signaling pathway. The research of this experiment may help to provide a new perspective and target for anti-hepatic fibrosis, whilst providing more experimental and theoretical basis for the clinical use of Sal B for liver fibrosis and protect liver function.

\section{Materials and methods}

Establishment of a rat model of liver fibrosis. All animal care and experimental procedures were approved by the Ethics Committee of Wannan Medical College (Anhui, China) and performed in accordance with the committee guidelines. A total of 32 male Sprague Dawley rats (6-7 weeks old with an average body weight of $172.3 \pm 5 \mathrm{~g}$ ) were provided by the Laboratory Animal Center of Zhejiang Academy of Medical Sciences [license no. SCXK (Zhejiang) 2019-0002]. All rats were placed under standard conditions at a stable temperature of $\left(24 \pm 2^{\circ} \mathrm{C}\right)$ with a relative humidity $45-60 \%$ and $12-\mathrm{h}$ light/dark cycle. They also had free access to water and standard food. After 1 week of adaptive feeding, rats were randomly divided into four groups as follows ( $\mathrm{n}=8$ each group): i) Normal control; ii) model; iii) positive control; and iv) Sal B group. Rats of the model, positive control and Sal B groups were injected subcutaneously in the abdomen region with $50 \%$ carbon tetrachloride $\left(\mathrm{CCl}_{4}\right) /$ corn oil solution at $1 \mathrm{ml} / \mathrm{kg}$ for 12 weeks (twice per week). An equivalent volume of normal saline was injected subcutaneously into the rats in the normal control group. From the 7 th week onwards, $0.1 \mathrm{mg} / \mathrm{kg}$ colchicine (cat. no. C90100; Shanghai Jizhi Biochemical Technology Co., Ltd.) (16) was administered to the positive control group by oral gavage for 6 weeks (once per day) and $60 \mathrm{mg} / \mathrm{kg}$ Sal B (cat. no. JKBm0226; Shanghai Jingke Chemical Technology Co., Ltd.) (17) was administered to the Sal B group by oral gavage once a day for 6 weeks. During the experiments, animals were weighed once a week and doses were adjusted based on body weight (according to the administration standard of colchicine $0.1 \mathrm{mg} / \mathrm{kg}$ or Sal B $60 \mathrm{mg} / \mathrm{kg}$ ). At $12 \mathrm{~h}$ after the final administration, rats were anesthetized by intraperitoneal injection of sodium pentobarbital $(40 \mathrm{mg} / \mathrm{kg})$. After taking $3 \mathrm{ml}$ of blood from the abdominal aorta with a blood sampling needle, the abdominal aorta was cut to allow for sacrifice of the rats by exsanguination. Finally, after the death of the rats was confirmed by respiratory and cardiac arrest, the liver tissues were collected.

Histopathological examination. Tissues were fixed with $4 \%$ paraformaldehyde using a portion of liver tissues from each group for $24 \mathrm{~h}$ at $4^{\circ} \mathrm{C}$. The fixed tissues were then dehydrated and paraffin embedded. Next, a Leica-RM2235 microtome (Leica Microsystems $\mathrm{GmbH}$ ) was used to slice the tissues to a thickness of $5 \mu \mathrm{m}$. The staining of three slices from each liver was performed using hematoxylin and eosin (H\&E), Sirius red and immunohistochemistry (IHC). For the H\&E staining procedure, paraffin slices were dewaxed in xylene for 6-10 min and then rehydrated with a descending ethanol gradient. At room temperature, the slices were placed in the hematoxylin solution for 8-12 $\mathrm{min}$, then rinsed with running water for 1-2 min, differentiated with $1 \% \mathrm{HCl}$-alcohol for $10-20 \mathrm{sec}$, rinsed again with running water and incubated with the eosin dye solution for 1-3 min. After ascending gradient alcohol dehydration, the slices were hyalinized in xylene and sealed with neutral gum. Sirius red staining was performed according to the protocols of the Sirius Red Stain Kit (cat. no. AG1470; Shanghai Jizhi Biochemical Technology Co., Ltd.).

For the IHC staining procedure, after dewaxing and hydration (identical to the $\mathrm{H} \& \mathrm{E}$ staining procedure), the tissue sections were incubated in $3 \% \mathrm{H}_{2} \mathrm{O}_{2}$-methanol at room temperature for 30 min. After washing with PBS, the sections were blocked with 5\% goat serum (cat. no. SL038; Beijing Solarbio Science \& Technology Co., Ltd.) for $12 \mathrm{~min}$ at room temperature and then incubated with the $\alpha$-SMA antibody (1:200; cat. no. bs-0189R; BIOSS) overnight at $4^{\circ} \mathrm{C}$. After washing with PBS, the sections were incubated with the secondary antibody (1:500; HRP-conjugated goat anti-rabbit IgG polymer; cat. no. 18001; Chengdu Zhengneng Biotechnology Co., Ltd.; https://en.zen-bio. cn/prod_view.aspx?TypeId=115\&Id=408364\&FId=t3:115:3) at room temperature for $40 \mathrm{~min}$. Subsequently, at room temperature, the sections were stained with DAB (Enhanced DAB chromogenic Kit; cat. no. DA1016; Beijing Solarbio Science $\&$ Technology Co., Ltd.) for $3 \mathrm{~min}$ and then counterstained with hematoxylin for $4 \mathrm{~min}$ at room temperature. The sections were then dehydrated with an ascending alcohol gradient and sealed using neutral gum. Finally, a light microscope was used to observe the sections and images (magnification, x100) were captured with an Olympus microscope (IXplore; Olympus Corporation).

Serum biochemistry. Blood that was collected from the abdominal aortas of anesthetized rats was centrifuged to separate the serum at $4^{\circ} \mathrm{C}$ at $1,000 \mathrm{x}$ g for $15 \mathrm{~min}$. An automatic biochemical analyzer Chemray 800 (Rayto Life and Analytical Sciences Co., Ltd.) was subsequently used to detect serum alanine aminotransferase (ALT), aspartate aminotransferase (AST), total bilirubin (TBIL) and albumin (ALB) levels.

Western blot analysis. After total protein was extracted by using RIPA buffer (cat. no. R0010; Beijing Solarbio Science $\&$ Technology Co., Ltd.) from the rat liver tissue $(50 \mathrm{mg})$ obtained from each group, the protein concentration was measured using a BCA Protein Assay Kit (cat. no. A53226; Thermo Fisher Scientific, Inc.). A total of $10 \mu \mathrm{g}$ protein was loaded onto a gel (10\% separated gel) for SDS-PAGE and transferred to PVDF membranes. The membranes were subsequently blocked with $5 \%$ skimmed milk for $2 \mathrm{~h}$ at $37^{\circ} \mathrm{C}$. After washing with TBS-Tween 20 (TBST, containing $0.05 \%$ Tween-20), the membranes were incubated with TGF- $\beta 1$ antibody (cat. no. 3711; 1:1,000; Cell Signaling Technology, Inc.) and $\beta$-actin antibody (cat. no. 4970; $1: 1,000$; Cell Signaling Technology, Inc.) overnight at $4^{\circ} \mathrm{C}$. The following day, HRP-conjugated Anti-rabbit $\operatorname{lgG}$ antibody (cat. no. 7074; 1:2,000; Cell Signaling Technology, Inc.) were applied to 
Table I. Primer Information.

\begin{tabular}{|c|c|c|c|c|}
\hline Gene & Accession number & Sequence $\left(5^{\prime} \rightarrow 3^{\prime}\right)$ & $\mathrm{Tm}$ & PL (bp) \\
\hline \multirow[t]{2}{*}{ Shh } & \multirow[t]{2}{*}{ NM_017221.1 } & F: TCAAGTCCAGCTGAAGTCCG & 59.68 & \multirow[t]{2}{*}{88} \\
\hline & & R: TTTCCCGGTTGCTTATCTGG & 57.88 & \\
\hline \multirow[t]{2}{*}{ Ptch1 } & \multirow[t]{2}{*}{ NM_001389256 } & F: ACGCTCCTTTCCTCTTGAGAC & 59.73 & \multirow[t]{2}{*}{168} \\
\hline & & R: TGAACTGGGCAGCTATGAAGT & 59.37 & \\
\hline \multirow[t]{2}{*}{ Smo } & \multirow[t]{2}{*}{ NM_012807.1 } & F: TCCATTTCTCCCTGGTGCCT & 60.85 & \multirow[t]{2}{*}{122} \\
\hline & & R: AGTCCGAGTCTGCATCCAAG & 59.47 & \\
\hline \multirow[t]{2}{*}{ Gli1 } & \multirow[t]{2}{*}{ NM_001191910.1 } & F: AACTCCACGAGCACACAGG & 59.93 & \multirow[t]{2}{*}{106} \\
\hline & & R: GGCAGTCCGTCTCATACACA & 59.47 & \\
\hline \multirow[t]{2}{*}{$\beta$-actin } & \multirow[t]{2}{*}{ NM_031144.3 } & F: TTGCTGACAGGATGCAGAA & 56.96 & \multirow[t]{2}{*}{101} \\
\hline & & R: ACCAATCCACACAGAGTACTT & 56.57 & \\
\hline
\end{tabular}

Tm, melting temperature; PL, product length; F, forward; R, reverse.

the TBST-washed membranes and incubated at $37^{\circ} \mathrm{C}$ for $2 \mathrm{~h}$ After washing with TBST, Clarity ${ }^{\mathrm{TM}}$ Western ECL Substrate (cat. no. 1705060; Bio-Rad Laboratories, Inc.) was added to the membranes, and protein bands were analyzed using ImageJ software (version 1.8.0; National Institutes of Health).

$R T-q P C R$. A Total RNA Kit I (cat. no. R683 4-01; Omega Bio-Tek, Inc.) was used to extract total RNA from the liver tissues of rats in each group, after which the concentration was measured using a microplate reader. According to the instructions of the Universal RT-PCR Kit (cat. no. RP1105-50T; Beijing Solarbio Science \& Technology Co., Ltd.), $1 \mu \mathrm{g}$ total RNA was reverse transcribed into cDNA. The temperature protocol of reverse transcription was as follows: $42^{\circ} \mathrm{C}$ for $60 \mathrm{~min}$ followed by $70^{\circ} \mathrm{C}$ for $10 \mathrm{~min}$. Subsequently, according to the instructions of the SYBR green fluorescent quantitative kit (cat. no. BL698A; Biosharp Life Sciences), the mRNA expression levels of Sonic hedgehog (Shh), Ptch1, Smo and Gli1 were detected using qPCR. The StepOnePlus ${ }^{\mathrm{TM}}$ Real-Time PCR System (Thermo Fisher Scientific, Inc.) was then used to quantify mRNA levels. $\beta$-actin was used as a control to measure the mRNA expression levels of genes related to the Hh signaling pathway via the comparative $2^{-\Delta \Delta \mathrm{Cq}}$ method (18). The thermocycling conditions for qPCR were as follows: One cycle at $95^{\circ} \mathrm{C}$ for $5 \mathrm{~min}$; followed by 40 cycles at $95^{\circ} \mathrm{C}$ for $10 \mathrm{sec}, 60^{\circ} \mathrm{C}$ for $30 \mathrm{sec}$ and $72^{\circ} \mathrm{C}$ for $30 \mathrm{sec}$. The primer sequences of this study are shown in Table I.

Statistical analysis. Data were analyzed using GraphPad Prism 6 software (GraphPad Software, Inc.) and are presented as the mean \pm SD of three repeats. One-way ANOVA with Bonferroni post hoc test was used for multiple comparisons. $\mathrm{P}<0.05$ was considered to indicate a statistically significant difference.

\section{Results}

Sal B treatment inhibits the $\mathrm{CCL}_{4}$-induced histopathological deterioration of the liver. The results of $\mathrm{H} \& \mathrm{E}$ and sirius red staining revealed no liver fibrous tissue hyperplasia in the normal control group. However, the fibrotic liver tissue of the model group exhibited a large amount of hyperplasia. When compared with the model group, there was a marked reduction in fibrous tissue hyperplasia present in the positive control and Sal B groups. IHC results demonstrated that $\alpha$-smooth muscle actin (SMA) was not expressed in the liver tissues of the normal control group, whereas positive expression was present in the model, positive control and Sal B groups. Furthermore, in comparison with that in the Sal B and positive control groups, higher $\alpha$-SMA expression levels were present in the liver tissues of the model group (Fig. 1). These results suggest that $\mathrm{CCL}_{4}$-induced liver histological changes can be inhibited by Sal B.

Sal B treatment reduces liver damage caused by $\mathrm{CCl}_{4}$. Liver function serum marker analysis demonstrated that the serum levels of ALT, TBIL and AST were all significantly increased, while ALB levels were significantly decreased (all $\mathrm{P}<0.05)$ in the Sal B, model and positive control groups compared with the normal control group. In addition, when compared with the Sal B and positive control groups, significantly higher serum ALT, TBIL and AST levels, and significantly lower ALB levels, were observed in the model group (all $\mathrm{P}<0.05$ ). Serum ALT, AST, TBIL and ALB levels did not significantly differ between the positive control group and the Sal B group (Table II). The analysis of serum markers suggests that Sal B could protect and improve liver function.

TGF- $\beta 1$ protein expression levels. The protein expression levels of TGF- $\beta 1$ were analyzed using western blotting. The results demonstrated that when compared with the normal control group, TGF- $\beta 1$ expression levels were increased in the model, positive control and Sal $\mathrm{B}$ groups (all $\mathrm{P}<0.05$ ). Significantly higher TGF- $\beta 1$ levels were also observed in the model group compared with the positive control and Sal B groups (both $\mathrm{P}<0.05$ ). No marked differences in TGF- $\beta 1$ levels were present between the positive control group and the Sal B control group (Fig. 2A). This study further confirmed that TGF- $\beta 1$ is an effective cytokine in causing liver fibrosis.

Sal B inhibits the $\mathrm{CCl}_{4}$-induced activation of the Hh signaling pathway. The results of qPCR analysis indicated that compared with that in the normal control group, there was a 
Table II. Effects of Sal B on the serum indices of liver function in rats with liver fibrosis.

\begin{tabular}{|c|c|c|c|c|c|}
\hline Group & $\mathrm{N}$ & ALT, U/1 & AST, U/1 & $\mathrm{TBIL}, \mu \mathrm{mol} / 1$ & ALB, g/l \\
\hline Normal control & 8 & $38.84 \pm 4.38$ & $121.42 \pm 16.14$ & $0.76 \pm 0.27$ & $37.72 \pm 6.10$ \\
\hline Model & 8 & $193.48 \pm 12.15^{\mathrm{a}}$ & $378.97 \pm 53.58^{\mathrm{a}}$ & $25.47 \pm 5.96^{\mathrm{a}}$ & $21.79 \pm 3.18^{\mathrm{a}}$ \\
\hline Positive control & 8 & $91.14 \pm 9.86^{\mathrm{a}, \mathrm{b}}$ & $222.82 \pm 42.92^{\mathrm{a}, \mathrm{b}}$ & $16.74 \pm 4.36^{\mathrm{a}, \mathrm{b}}$ & $31.13 \pm 4.92^{\mathrm{a}, \mathrm{b}}$ \\
\hline Sal B & 8 & $87.68 \pm 9.21^{\mathrm{a}, \mathrm{b}}$ & $196.62 \pm 37.71^{\mathrm{a}, \mathrm{b}}$ & $14.79 \pm 3.91^{\mathrm{a}, \mathrm{b}}$ & $27.92 \pm 2.85^{\mathrm{a}, \mathrm{b}}$ \\
\hline
\end{tabular}

${ }^{\mathrm{a}} \mathrm{P}<0.05$ vs. the normal control group; ${ }^{\mathrm{b}} \mathrm{P}<0.05$ vs. the model group. Data are presented as the mean $\pm \mathrm{SD}$. ALT, alanine aminotransferase; AST, aspartate aminotransferase; TBIL, total bilirubin; ALB, albumin; Sal B, salvianolic acid.
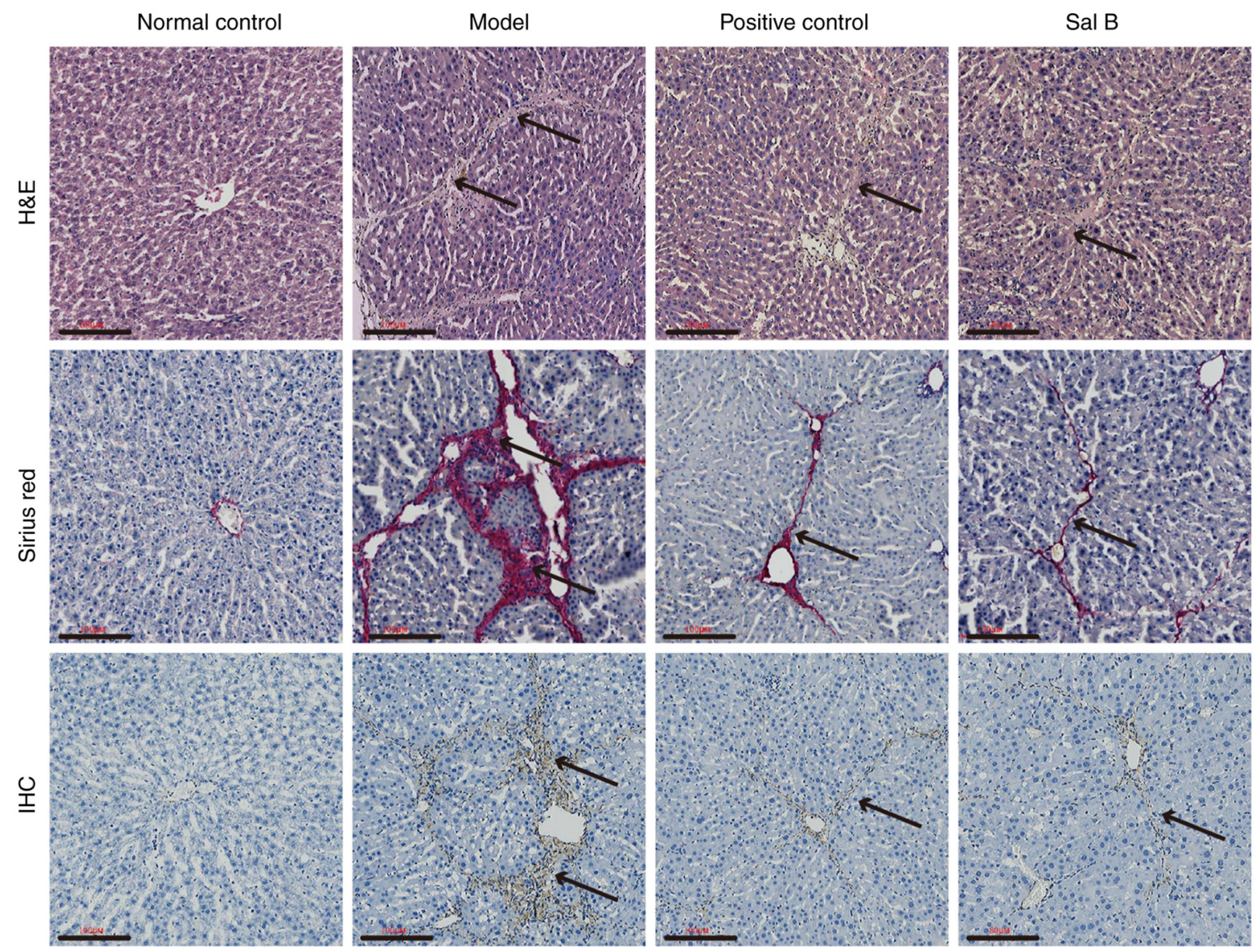

Figure 1. Histopathological images of rat liver tissue. H\&E staining revealed hyperplastic fibrous tissue in a cord-like structure. Fibrous tissue was stained red following sirius red staining. IHC results revealed the presence of $\alpha$-smooth muscle actin through a yellowish-brown stain. Black arrows indicate hyperplastic fibrous tissue or expressed $\alpha$-smooth muscle actin. Scale bar, $100 \mu \mathrm{m}$. H\&E, hematoxylin \& eosin; IHC, immunohistochemistry; Sal B, salvianolic acid B.

significant increase in Shh, Ptch1, Smo and Gli1 expression levels in the model, positive control and Sal B groups (all $\mathrm{P}<0.05)$. Furthermore, increased levels of Shh, Ptch1, Smo and Gli1 expression levels were observed in the model group compared with the Sal B and positive control groups (all $\mathrm{P}<0.05)$. No significant differences in Shh, Ptch1, Smo and Glil mRNA levels were observed between the positive control group and the Sal B group (Fig. 2B). The aforementioned results revealed that $\mathrm{Hh}$ signaling pathway is involved in the process of liver fibrosis, where Sal B can inhibit the activation of Hh signaling pathway.

\section{Discussion}

Liver fibrosis is a serious health problem, which can further develop into liver cirrhosis or even hepatocellular carcinoma if it is not treated in a timely and effective manner $(19,20)$. However, as this process is reversible $(4,19)$, it is vitally important to slow or reverse the development of liver fibrosis when treating various chronic liver diseases, such as autoimmune hepatitis, cholestatic liver diseases and non-alcoholic fatty liver disease, and to reduce the occurrence of cirrhosis. This has therefore become an important topic in current medical research. 

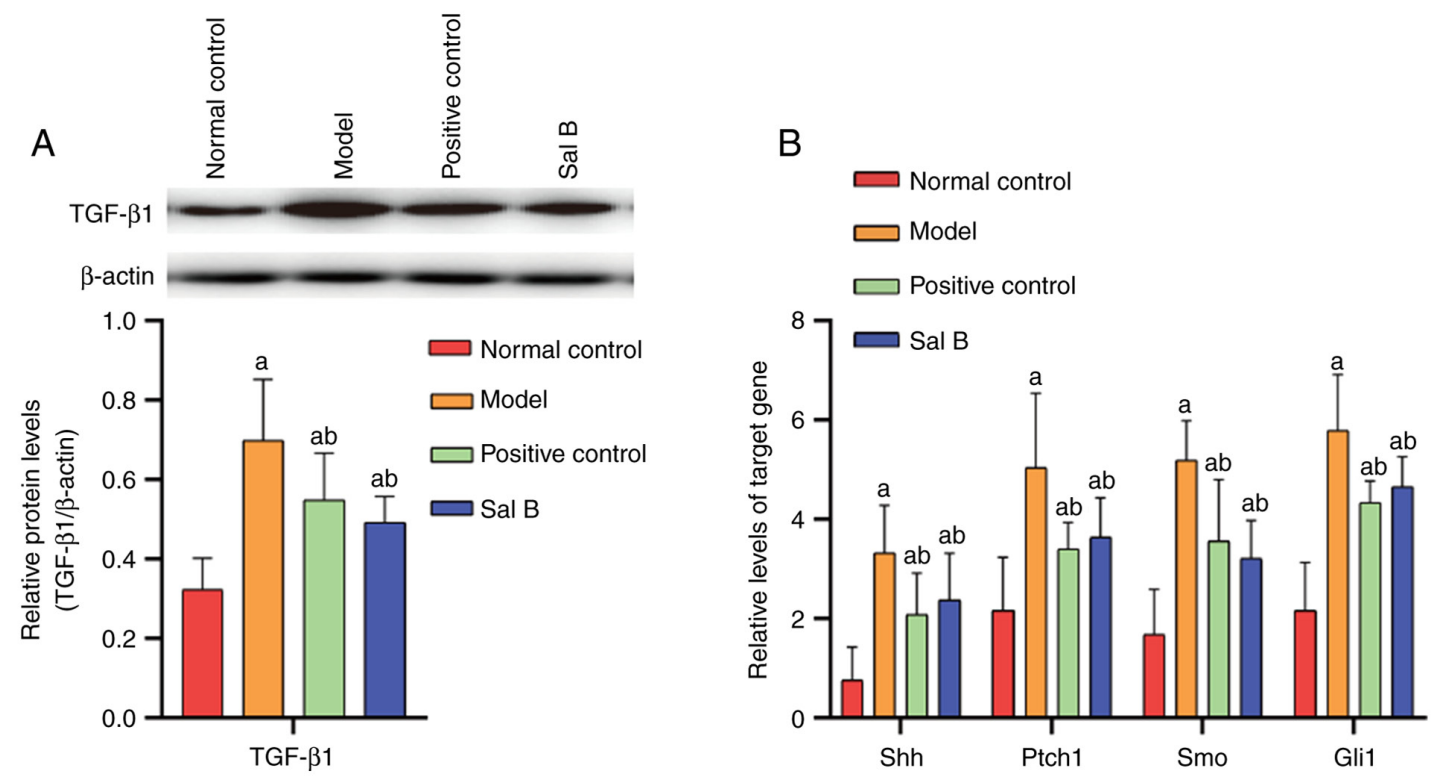

Figure 2. Protein and mRNA expression levels of liver fibrosis-related genes. (A) Representative blots and subsequent quantification of TGF- $\beta 1$ protein expression levels. (B) mRNA expression levels of Hh signaling pathway-related genes. ${ }^{\mathrm{a}} \mathrm{P}<0.05 \mathrm{vs}$. normal control group; ${ }^{\mathrm{b}} \mathrm{P}<0.05 \mathrm{vs}$. model group. Sal $\mathrm{B}$, salvianolic acid B; Shh, Sonic hedgehog; Ptch1, patched homolog 1; Smo, smoothened; Gli1, glioma-associated oncogene homolog 1.

The incidence and progression of liver fibrosis is a complex pathological process that involves a series of cytokines and multiple signaling pathways (21). For example, oxidative stress is an important factor in promoting inflammation and fibrosis (22). A previous study revealed that during liver fibrosis, the mitochondrial function of liver cells is impaired and the regulatory abilities of AMP-activated protein kinase/peroxisome proliferator-activated receptor $\alpha$ are decreased (23). Additional studies have also demonstrated that mitochondria produce excessive superoxide anions, hydrogen peroxide and other reactive oxygen species, with the accumulation of the latter causing further damage to mitochondria and oxidative stress damage to liver tissue $(23,24)$. Oxidative stress can activate NF- $\mathrm{kB}$, nuclear factor-erythroid-related factor 2 and other pathways to regulate gene transcription, protein expression, cell apoptosis and the activation of HSCs (25-27). HSC activation is critical to the incidence of liver fibrosis $(5,28)$. When the liver is stimulated by various pathogenic factors, such as ethanol, drugs, toxins or viruses, HSCs are activated and transform into MFBs that secrete large quantities of collagen to disrupt the balance of the ECM. This causes liver parenchyma to be replaced by progressively increasing quantities of ECM, and gradually leads to the formation of liver fibrosis $(29,30)$. A previous study has demonstrated that upregulated levels of $\alpha$-SMA (a marker of HSC activation) are present in the liver tissues of fibrotic rats and that Sal B can inhibit HSC activation, thereby reducing the expression of $\alpha$-SMA (14). In the present study, immunohistochemical staining was performed for $\alpha$-SMA in the liver tissue of each group of rats. The results revealed no $\alpha$-SMA staining in the normal control group, whereas positive staining was observed in the model, positive control and Sal B groups. Furthermore, compared with those in the positive control and Sal B groups, evidently higher $\alpha$-SMA expression levels were observed in the model group, further confirming that activated HSCs were present in the pathological liver tissues of rats. HSC activation and $\alpha$-SMA expression were also suppressed by Sal B, which hindered liver fibrosis.

Sal B exhibits strong antioxidant activity and has been widely studied in the treatment of chronic liver disease (31). For example, in the livers of rats with non-alcoholic steatohepatitis, Sal B can improve the structure and function of the mitochondria by upregulating the expression of mitofusin-2, so as to reduce the liver tissue damage induced by oxidative stress (31). It has also been reported that Sal B can inhibit the progression of liver fibrosis in rats by regulating the $\mathrm{NF}-\kappa \mathrm{B} / \mathrm{I} \kappa \mathrm{B} \alpha$ signaling pathway, whilst significantly reducing the serum levels of ALT, TBIL and AST in rats with liver fibrosis (32). The present study determined that Sal B could significantly reduce serum ALT, TBIL and AST levels, and increase ALB levels, in the rat of model of liver fibrosis. These results are consistent with those already mentioned, indicating that Sal B plays an important role in protecting liver function.

The highly conserved Hh signaling pathway is critical to tissue renewal, damage repair and embryonic development (33). Studies have demonstrated that abnormal activation of the Hh signaling pathway is intricately associated with liver cancer, liver fibrosis and non-alcoholic fatty liver $(34,35)$. However, there are few studies on the effects of Sal B on the Hh signaling pathway in liver fibrosis. In the present study, Sal B was used for the treatment of liver fibrosis in rats. The results revealed that Sal B reduced Shh, Ptch1, Smo and Gli1 mRNA expression levels in the liver tissues in the model group, thereby inhibiting HSC activation.

HSCs can be activated by TGF- $\beta 1$, which is regarded as the most effective cytokine involved in the development of liver fibrosis (36). A previous study has demonstrated that the levels of TGF- $\beta 1$ in liver tissues is positively associated with activation of the Hh signaling pathway (37). The present study demonstrated that upregulated Hh signaling pathway-associated genes and TGF- $\beta 1$ expression levels were present in the 
liver tissue of fibrotic rats, with Sal B treatment negatively regulating their expression.

Currently, to the best of our knowledge, only the study by $\mathrm{Yu}$ et al (15) has investigated whether Sal B can inhibit HSC activation and proliferation by interfering with the $\mathrm{Hh}$ signaling pathway. The results revealed that Sal B induced microRNA-152, leading to the silencing of DNA methyltransferase 1-mediated Ptch1 demethylation, thereby inhibiting liver fibrosis. In the study, a mouse model of hepatic fibrosis was established and the effects of Sal B on the histological structure of the liver, along with the expression levels of a-SMA and type I collagen, were detected. The effect of Sal B on the expression of Ptch1, Smo, and Gli2 genes in the HSCs of mice with hepatic fibrosis was also detected by qPCR (15). In the current study, a rat model of hepatic fibrosis was established and the effects of Sal B on the histological structure of the liver, the expression levels of Shh, Ptch1, Smo and Gli1 genes associated with the Hh signaling pathway, and serum markers of liver injury were detected. By assessing the whole Hh signaling pathway, the present study aimed to clarify whether Sal B can reverse liver fibrosis in rats through the $\mathrm{Hh}$ signaling pathway.

In summary, the anti-fibrotic effect of Sal B may be partly mediated through the downregulation of TGF- $\beta 1$ and by decreasing the activation of the Hh signaling pathway, thereby inhibiting the activation of HSCs, which are the key cells involved in the development of the fibrotic environment. The results may provide an experimental basis for the treatment of liver fibrosis. In addition, the potential clinical value of Sal B for the treatment of liver fibrosis and its protective effects on liver function were theoretically confirmed by the present study. As aforementioned, both mitochondrial dysfunction and oxidative stress are involved in the process of liver fibrosis. Therefore, future studies should explore the effect of Sal B on liver mitochondrial function and the oxidative stress response in liver fibrosis through in vivo and in vitro experiments. Additionally, it should be determined whether there is an association between the Hh signaling pathway, mitochondrial dysfunction and the oxidative stress response.

\section{Acknowledgements}

Not applicable.

\section{Funding}

This study was supported by the Young and Middle-Aged Research Foundation (grant no. WK201810) and the Key Scientific Research Foundation of Wannan Medical College (grant no. WK2021Z11).

\section{Availability of data and materials}

The datasets used and/or analyzed during the current study are available from the corresponding author on reasonable request.

\section{Authors' contributions}

ST, RD and TL conceived and designed the study. ST, RD, TX, JH, WG and AL performed the experiments. ST wrote the manuscript. LL, HH and JL performed the statistical analysis and drafted the manuscript. RD and TL confirmed the authenticity of all the raw data. All authors have read and approved the final manuscript.

\section{Ethics approval and consent to participate}

All animal care and experimental procedures were performed in accordance with the guidelines of the Ethics Committee of Wannan Medical College (Anhui, China). The same committee provided ethical approval.

\section{Patient consent for publication}

Not applicable.

\section{Competing interests}

The authors declare that they have no competing interests.

\section{References}

1. Bellan M, Castello LM and Pirisi M: Candidate biomarkers of liver fibrosis: A concise, pathophysiology-oriented review. J Clin Transl Hepatol 6: 317-325, 2018.

2. Wan SZ, Liu C, Huang CK, Luo FY and Zhu X: Ursolic acid improves intestinal damage and bacterial dysbiosis in liver fibrosis mice. Front Pharmacol 10: 1321, 2019.

3. Atta HM: Reversibility and heritability of liver fibrosis: Implications for research and therapy. World J Gastroenterol 21: 5138-5148, 2015.

4. Trautwein C, Friedman SL, Schuppan D and Pinzani M: Hepatic fibrosis: Concept to treatment. J Hepatol 62 (Suppl 1): S15-S24, 2015.

5. Elpek GO: Cellular and molecular mechanisms in the pathogenesis of liver fibrosis: An update. World J Gastroenterol 20: 7260-7276, 2014

6. Phaosri M, Jantrapirom S, Takuathung MN, Soonthornchareonnon N, Sireeratawong S, Buacheen P, Pitchakarn P, Nimlamool W and Potikanond S: Salacia chinensis L. stem extract exerts antifibrotic effects on human hepatic stellate cells through the inhibition of the TGF- $\beta 1$-induced SMAD2/3 signaling pathway. Int J Mol Sci 20: 6314, 2019.

7. Gandhi CR: Hepatic stellate cell activation and pro-fibrogenic signals. J Hepatol 67: 1104-1105, 2017.

8. Singh R and Lauth M: Emerging roles of DYRK kinases in embryogenesis and hedgehog pathway control. J Dev Biol 5: 13, 2017.

9. Abramyan J: Hedgehog signaling and embryonic craniofacial disorders. J Dev Biol 7: 9, 2019.

10. Michelotti GA, Xie G, Swiderska M, Choi SS, Karaca G, Krüger L, Premont R, Yang L, Syn WK, Metzger D and Diehl AM: Smoothened is a master regulator of adult liver repair. J Clin Invest 123: 2380-2394, 2013.

11. Zheng Z, Wang Y, Yu H, Li W, Wu J, Cai C and He Y: Salvianolic acid $\mathrm{B}$ inhibits ototoxic drug-induced ototoxicity by suppression of the mitochondrial apoptosis pathway. J Cell Mol Med 24: 6883-6897, 2020.

12. Ren Y, Tao S, Zheng S, Zhao M, Zhu Y, Yang J and Wu Y: Salvianolic acid B improves vascular endothelial function in diabetic rats with blood glucose fluctuations via suppression of endothelial cell apoptosis. Eur J Pharmacol 791: 308-315, 2016.

13. Lu XL, Dong XY, Fu YB, Cai JT, Du Q, Si JM and Mao JS: Protective effect of salvianolic acid B on chronic pancreatitis induced by trinitrobenzene sulfonic acid solution in rats. Pancreas 38: 71-77, 2009.

14. Zhang W, Ping J, Zhou Y, Chen G and Xu L: Salvianolic acid $\mathrm{B}$ inhibits activation of human primary Hepatic stellate cells through downregulation of the myocyte enhancer factor 2 signaling pathway. Front Pharmacol 10: 322, 2019.

15. Yu F, Lu Z, Chen B, Wu X, Dong P and Zheng J: Salvianolic acid B-induced microRNA-152 inhibits liver fibrosis by attenuating DNMT1-mediated Patched1 methylation. J Cell Mol Med 19: 2617-2632, 2015 . 
16. Kim S, Jung ES, Lee J, Heo NJ, Na KY and Han JS: Effects of colchicine on renal fibrosis and apoptosis in obstructed kidneys. Korean J Intern Med 33: 568-576, 2018.

17. Liu H, Liu W, Qiu H, Zou D, Cai H, Chen Q, Zheng C and $\mathrm{Xu}$ D: Salvianolic acid B protects against myocardial ischaemia-reperfusion injury in rats via inhibiting high mobility group box 1 protein expression through the PI3K/Akt signalling pathway. Naunyn Schmiedebergs Arch Pharmacol 393: 1527-1539, 2020.

18. Livak KJ and Schmittgen TD: Analysis of relative gene expression data using real-time quantitative PCR and the 2(-Delta Delta C(T)) Method. Methods 25: 402-408, 2001.

19. Sun M and Kisseleva T: Reversibility of liver fibrosis. Clin Res Hepatol Gastroenterol 39 (Suppl 1): S60-S63, 2015.

20. Bansal R, Nagorniewicz B and Prakash J: Clinical advancements in the targeted therapies against liver fibrosis. Mediators Inflamm 2016: 7629724, 2016.

21. Josan S, Billingsley K, Orduna J, Park JM, Luong R, Yu L, Hurd R, Pfefferbaum A, Spielman D and Mayer D: Assessing inflammatory liver injury in an acute $\mathrm{CCl} 4$ model using dynamic 3D metabolic imaging of hyperpolarized [1-(13)Clpyruvate. NMR Biomed 28: 1671-1677, 2015.

22. Cheresh P, Kim SJ, Tulasiram S and Kamp DW: Oxidative stress and pulmonary fibrosis. Biochim Biophys Acta 1832: 1028-1040, 2013.

23. Echeverría F, Valenzuela R, Bustamante A, Álvarez D, Ortiz M, Espinosa A, Illesca P, Gonzalez-Mañan D and Videla LA: High-fat diet induces mouse liver steatosis with a concomitan decline in energy metabolism: Attenuation by eicosapentaenoic acid (EPA) or hydroxytyrosol (HT) supplementation and the additive effects upon EPA and HT co-administration. Food Funct 10: 6170-6183, 2019.

24. Ortiz M, Soto-Alarcón SA, Orellana P, Espinosa A, Campos C, López-Arana S, Rincón MA, Illesca P, Valenzuela R and Videla LA: Suppression of high-fat diet-induced obesity-associated liver mitochondrial dysfunction by docosahexaenoic acid and hydroxytyrosol co-administration. Dig Liver Dis 52: 895-904, 2020

25. Valenzuela R and Videla LA: Impact of the Co-Administration of N-3 fatty acids and olive oil components in preclinical nonalcoholic fatty liver disease models: A mechanistic view. Nutrients 12: 499, 2020.

26. Ni YH, Huo LJ and Li TT: Antioxidant axis Nrf2-keap1-ARE in inhibition of alcoholic liver fibrosis by IL-22. World J Gastroenterol 23: 2002-2011, 2017.
27. Valenzuela R and Videla LA: Crosstalk mechanisms in hepatoprotection: Thyroid hormone-docosahexaenoic acid (DHA) and DHA-extra virgin olive oil combined protocols. Pharmacol Res 132: 168-175, 2018.

28. Liang JX, Qu XF, Zeng WT, Zhu KL, Zhang H and Wei JJ Mechanism of oxymatrine in preventing hepatic fibrosis formation in patients with chronic hepatitis B. Nan Fang Yi Ke Da Xue Xue Bao 30: 1871-1873, 2010 (In Chinese).

29. Seki E and Brenner DA: Recent advancement of molecular mechanisms of liver fibrosis. J Hepatobiliary Pancreat Sci 22 512-518, 2015.

30. Li D, He L, Guo H, Chen $\mathrm{H}$ and Shan $\mathrm{H}$ : Targeting activated hepatic stellate cells (aHSCs) for liver fibrosis imaging. EJNMMI Res 5: 71, 2015.

31. Wang YC, Kong WZ, Jin QM, Chen J and Dong L: Effects of salvianolic acid B on liver mitochondria of rats with nonalcoholic steatohepatitis. World J Gastroenterol 21: 10104-10112, 2015.

32. Wang R, Yu XY, Guo ZY, Wang YJ, Wu Y and Yuan YF: Inhibitory effects of salvianolic acid $\mathrm{B}$ on $\mathrm{CCl}(4)$-induced hepatic fibrosis through regulating $\mathrm{NF}-\kappa \mathrm{B} / \mathrm{I} \kappa \mathrm{B} \alpha$ signaling. J Ethnopharmacol 144: 592-598, 2012.

33. Skoda AM, Simovic D, Karin V, Kardum V, Vranic S and Serman L: The role of the Hedgehog signaling pathway in cancer: A comprehensive review. Bosn J Basic Med Sci 18: 8-20, 2018.

34. Kumar V, Dong Y, Kumar V, Almawash S and Mahato RI: The use of micelles to deliver potential hedgehog pathway inhibitor for the treatment of liver fibrosis. Theranostics 9: 7537-7555, 2019.

35. Gao L, Zhang Z, Zhang P, Yu M and Yang T: Role of canonical Hedgehog signaling pathway in liver. Int J Biol Sci 14: 1636-1644, 2018.

36. Ghafoory S, Varshney R, Robison T, Kouzbari K, Woolington S, Murphy B, Xia L and Ahamed J: Platelet TGF- $\beta 1$ deficiency decreases liver fibrosis in a mouse model of liver injury. Blood Adv 2: 470-480, 2018

37. El-Agroudy NN,El-Naga RN,El-Razeq RA and El-Demerdash E: Forskolin, a hedgehog signalling inhibitor, attenuates carbon tetrachloride-induced liver fibrosis in rats. Br J Pharmacol 173: 3248-3260, 2016.

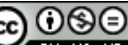

This work is licensed under a Creative Commons Attribution-NonCommercial-NoDerivatives 4.0 International (CC BY-NC-ND 4.0) License. 